\title{
EDUCAÇÃO AMBIENTAL UMA PROPOSTA EMANCIPATÓRIA NA EDUCAÇÃO FÍSICA ESCOLAR
}

\author{
ENVIRONMENTAL EDUCATION AN EMANCIPATORY PROPOSAL IN \\ SCHOOL PHYSICAL EDUCATION
}

\author{
Reard Michel dos Santos \\ Mestre Profissional no Ensino das Ciências Ambientais \\ Secretaria Municipal da Educação de Curitiba. \\ Curitiba, Paraná - Brasil. \\ reardmichel@gmail.com \\ Ernesto Jacob Keim \\ Doutor em Educação - Unimep \\ Professor da Universidade Federal do Paraná - Centro de Estudos do Mar. \\ Pontal do Paraná, Paraná - Brasil. \\ ernestojacobk@gmail.com \\ Soraya Corrêa Domingues \\ Doutora em Educação Física - UFSC \\ Professora da Universidade Federal do Paraná - Departamento de Educação Física. \\ Curitiba, Paraná - Brasil. \\ pajaritovuela@gmail.com
}

\begin{abstract}
Resumo: A temática ambiental conquista espaço no contexto educacional como tema transversal. Para contribuir neste debate, o presente artigo tem como objetivo entender a Educação Física a partir da abordagem da Ciência da Motricidade Humana como proposta Emancipatória a favor da Vida. A metodologia é do tipo pesquisa social qualitativa que desenvolveu estudo teórico exploratório sobre a Educação Física e a Educação Ambiental. As análises do estudo apontam como resultados a necessidade de uma leitura questionadora das competências da Base Nacional Comum Curricular, indicando processos educativos emancipatórios ao evidenciar o axioma da transcendência, de ser mais, e da autossuperação. Como conclusão, compreende-se que a Educação Física pode ser um componente curricular de valorização do movimento humano, da construção do corpo e da saúde, e da possibilidade de desenvolver ações em que, a criatividade, a autonomia e o senso de pertencimento, possam ser vivenciados como processos educativos dinâmicos nas práticas corporais.
\end{abstract}

Palavras chave: educação física; motricidade humana; educação ambiental; emancipação.

Abstract: The environmental theme gains space in the educational context as a cross-cutting theme. For contributing to this debate, this article aims to understand Physical Education from the science of Human Motricity perspective as an emancipatory proposal in favor of Life. The methodology is qualitative social research that developed an exploratory theoretical study on Physical Education and Environmental Education. As a result, the analysis of the study points out the need for a questioning reading of the competencies of the Common National Curriculum Base, indicating emancipatory educational processes by highlighting the axiom of transcendence, of being more, and of self-overcoming. In conclusion, it is understood that Physical Education can be a curricular component of valuing the human movement, of the body and of health construction, and of the possibility of developing actions in which, creativity, autonomy, and the sense of belonging, can be experienced as dynamic educational processes in bodily practices.

Key-words: physical education; human motricity; environmental education; emancipation.

Cite como

\section{(ABNT NBR 6023:2018)}

SANTOS, Reard Michel dos; KEIM, Ernesto Jacob; DOMINGUES, Soraya Corrêa. Educação ambiental uma proposta emancipatória na educação física escolar. Dialogia, São Paulo, n. 38, p. 1-16, e18614, maio/ago. 2021. Disponível em: https://doi.org/10.5585/38.2021.18614.

American Psychological Association (APA)

Santos, R. M. dos., Keim, E. J., \& Domingues, S. C. (2021, maio/ago.). Educação ambiental uma proposta emancipatória na educação física escolar. Dialogia, São Paulo, 38, p. 1-16, e18614. https://doi.org/10.5585/38.2021.18614. 


\section{Introdução}

Desde o nascimento e por toda a existência, a pessoa, de forma gradual, adquire consciência da sua presença no mundo, o que fundamenta assumir o poder pessoal e, consequentemente, a responsabilização pelas escolhas e decisões, bem como o reconhecimento de sua inserção no processo de humanização, ao evidenciar a necessidade da interação e interdependência com tudo e todos, construindo a história individual com repercussão no coletivo.

Nessa dinâmica, a presença do ser humano no mundo se firma com a necessidade de agir, pelo e no movimento próprio, ao caminhar, dançar, jogar, conversar, trabalhar, relacionar, imaginar, examinar, amar, a vida acontece na existência corporal em contexto histórico, cultural e social.

Entretanto, na vida em sociedade os mecanismos hegemônicos tensionam a relação entre o ser social e o ser individual, de tal forma que as forças e os poderes dominantes na sociedade, permeados pelos referenciais da economia, da tecnologia e da legislação, promovem o acirramento da divisão entre classes sociais. A tensão decorrente dos processos produtivos e orientados para atender diferenças de classes, geram meios de produção que causam a destruição dos recursos naturais, e ditam padrões estereotipados de comportamentos, inculcando o individualismo, a competição, o consumismo e o autoritarismo (DOMINGUES, 2021).

No campo da Educação Física, os valores hegemônicos se estabelecem nos conteúdos teóricos e nas repetições mecânicas das práticas corporais, utilizando a estratégia técnicoinstrumental no processo de ensino, que exerce controle e disciplinamento dos corpos. Esse processo de civilizar o ser humano pelo controle e pela formação de sua subjetividade, gera um ser acrítico, mantendo-o afastado do real e do sensível, desvalorizando sua própria cultura e o seu modo de agir, pensar e sentir de tal forma que fragmenta o sujeito e o conhecimento, promovendo a ignorância (KUNZ, 2004).

A educação nesse contexto, ao agir como agente de libertação, Emancipação e valorização da vida, desenvolve-se por meio de processo dinâmico de interações e mudanças, que desafiam o momento e as circunstâncias pelas quais determinadas comunidades se organizam (KEIM, 2014). "Entender como a subjetividade é desenvolvida torna-se imperativo para entender-se como a subjetividade dominada pode ser libertada” (KUNZ, 2004, p. 110).

Diante desse jogo de forças, o professor ocupa um papel fundamental ao reescrever as políticas de educação com a sua leitura de mundo, a qual impulsiona a sua forma de educar e agir. No propósito de realizar uma prática de educação corporal integral e Emancipatória, este estudo tem como objetivo entender a Educação Física a partir da abordagem da Ciência da Motricidade 
Humana como proposta Emancipatória a favor da Vida, fundamentada na fenomenologia desenvolvida por Merleau-Ponty (1975, 2000, 2006) e na hermenêutica (SÉRGIO, 1995), como uma possibilidade de tematizar as unidades de ensino do componente curricular da Educação Física, a partir de uma leitura questionadora e crítica das competências citadas pela Base Nacional Comum Curricular, na intenção de compreender a interação da pessoa com o mundo.

Atualmente a Educação Física, de acordo com a Base Nacional Comum Curricular (BRASIL, 2018), configura-se como um componente curricular obrigatório no Ensino Fundamental. Na escola, a aplicabilidade desse documento não deve ser realizada de forma direta. Para Neira (2018) é um documento que apresenta problemas e precisa ser lido de forma crítica e questionadora, evitando a reprodução de uma pedagogia neotecnicista (SAVIANI, 2008 apud NEIRA, 2018, p. 02).

Nessa perspectiva crítica e questionadora, o processo investigativo que sustenta esse texto (SANTOS, 2019) tem base na estrutura da pesquisa social (CRESWEEL, 2010), que dialoga teoricamente com abordagem da Ciência da Motricidade Humana, para indicar possíveis caminhos para as práticas corporais da Educação Física escolar, a saber: brincadeiras e jogos, esportes, ginásticas, danças, lutas e as práticas corporais de aventura.

Com a proposta da Emancipação das ações humanas a favor da vida, a Ciência da Motricidade Humana entende a totalidade humana com base nos seguintes elementos: corpomente-desejo-natureza-sociedade. Com esses pressupostos, ela aponta que é impossível isolar a pessoa do seu ecossistema; o indivíduo da sociedade e da natureza; e o sujeito do objeto, além de considerar o sujeito em sua dimensão física e em relação aos elementos que o compõem (SÉRGIO, 2010).

A Ciência da Motricidade Humana perante a necessidade da criação da consciência corporal dos estudantes, e do reconhecimento generalizado da importância e significado do corpo, parte do princípio de que tudo em nós é processo e, como tal, a transcendência e a autossuperação são condições do nosso aprimoramento (SÉRGIO, 1995).

Compreender o corpo em movimento, ou seja, o ser humano pelo viés da Motricidade Humana se faz imprescindível, para o contexto educacional se sustentar em uma concepção de ambiente no qual estamos inseridos. Nesse sentido, optamos pela proposta da Educação da Emancipação a favor da Vida (KEIM, 2019a). Essa abordagem se refere, neste texto, ao que é conhecido como Educação Ambiental, e tem o propósito de consolidar a relação humana com os ambientes planetários, movido pela amorosidade e dignidade, constituindo-se como postura de responsabilidade com a vida, cujo processo está em constante metamorfose. 
A complexidade dessa proposta educativa remete a uma posição pela qual a vida é posta como referencial prioritário, na medida em que as relações interpessoais se fundamentam em percepção do mundo, como espaço e tempo a ser lido, isto é, tempo e espaço que consolidam conhecimentos, como afirma a Pedagogia Freiriana, com foco anticolonial e referendado nos pressupostos que caracterizam os Princípios Eco-Vitais (KEIM, 2019a).

Essas abordagens de educação encontram eco na visão de Domingues (2011, p. 82), ao pesquisar as aproximações da Educação Física com os temas ambientais e de preservação da vida, implicando construção de outro espaço pedagógico, no qual o mundo seja potência e possibilidade de construção de conhecimento em outra lógica. Com base nessa constatação, a pesquisadora revela que as pequenas ações do Eu-Mundo, ou seja, as ações de cada ser humano com intencionalidade de produzir impactos são relevantes e podem alterar a organização da estrutura socioeconômica.

Nesse sentido, a Educação Ambiental é uma Educação da Emancipação a favor da Vida que se apresenta como uma possibilidade de educar as novas gerações para um engajamento com o mundo, de maneira indissociável, de forma a não separar o pensar, o fazer e o sentir, por meio do qual seus conjuntos de saberes possam desencadear transformações na estrutura social que envolve linguagem e ação.

Após a Rio-92, o cenário para Educação Ambiental apresentou avanços significativos na educação brasileira, com parâmetros legislativos que garantem o caráter integrador, constante e ininterrupto, ao contemplar, como dimensão da educação, uma complexidade de saberes, conhecimentos e fazeres inter-relacionados, que possibilitam o desenvolvimento do trabalho pedagógico na perspectiva interdisciplinar e transversal (BRASIL, 2012). Assim, o desafio de construir uma proposta curricular na qual a temática ambiental e de preservação da vida, sejam abordadas como elemento transversal nos processos formativos, caracterizam-se como postura de responsabilidade social.

Educação da emancipação a favor da vida: um apelo por amorosidade e dignidade

A Educação da Emancipação a favor da Vida, aqui compreendida como Educação Ambiental, direciona o foco na reflexão sobre a responsabilidade dos humanos com a vida, na perspectiva de reconhecer o que significa emancipar e o que significa vida com dignidade (KEIM, 2019a).

A proposta de Keim (2019a) se confronta com o significado literal de Educação Ambiental, que se caracteriza como uma postura para educar o ambiente, e o ser humano, como parte desse 
meio, para suportar os desmandos decorrentes das ações humanas institucionalizadas, especialmente pela ideologia do mercado, tais como: produção de alimento exclusivamente para especulação financeira e não voltada para amenizar o problema da fome; desmatamento das florestas e ampliação das monoculturas; envenenamento do solo e da água entre tantas alterações invasivas que interferem em aspectos cruciais à vida.

A Educação da Emancipação a favor da Vida caracteriza-se como uma abordagem educativa com foco na Emancipação, a qual almeja consolidar a relação humana com ambientes planetários, movido pela amorosidade e dignidade, constituindo-se como postura de responsabilidade com a vida, cujo processo está em constante metamorfose. Essa abordagem educativa se fundamenta nos referenciais freirianos, na educação anticolonial que, segundo Keim (2019a), podem ser referenciados pela fenomenologia Schiller-Goethiana e nos princípios EcoVitais.

Com base nos referenciais freirianos, esta proposta educativa se configura como esperança, ao considerar a necessidade de cada pessoa se reconhecer como ser político, para então promover mudanças no modelo civilizatório no qual estão imersos (KEIM, 2019a). Esta ação, implica promover uma dinâmica que contemple a compreensão de que a educação é algo maior e mais complexo que a escolarização.

Nesse sentido, dialogamos com Paulo Freire (2005), que aponta a dimensão ontológica do ser humano como seres que se educam, pois se apresentam como geradores e promotores de libertação e autonomia, com vocação para Ser Mais a favor da vida com dignidade, pois são: incompletos, porque estão em permanente relação; inacabados, por saberem que sempre podem ser diferente; e inconclusos, por saberem que estão em permanente processo de ecorreorganização (desorganização e organização) nas relações sociais e planetárias.

Nos aspectos referente à posição de educação anticolonial, diante da tríade: colonização, colonizador e colonizado, temos em Keim (2018a), argumentos que explicam a colonização como processo, em que um agente externo impõe suas marcas, de forma a serem elas as que devem ser seguidas, normalmente para ganhar alguma vantagem. Assim, diante do processo colonialista, a cultura e a cosmovisão do colonizador são propagadas pelo colonizado, o qual muitas vezes não se dá conta de estar exercendo essa função de multiplicador e repassador da visão e desejos do colonizador.

Com base nessas premissas destacamos três referenciais que sinalizam como um processo de educação anticolonial pode romper com padrões postos pelo projeto colonizador, na medida em que: 
-...valoriza as pessoas para superar as diferenças de classes. De forma que a escola deva mediar essa posição social e adequar a sociedade ao homem e não o homem à sociedade. - ...estimula cada pessoa a se compreender como alguém, que está a todo tempo construindo seu próprio caminho. O ser humano, no processo anticolonial está em caminho de si próprio.

- ...pode emancipar o ser humano para a dimensão planetária de forma a se comprometer com a vida, se colocando como parte, e não como o centro de todo o processo vital. (KEIM, 2018a, p. 23).

Com esses argumentos, a Educação da Emancipação a favor da Vida tem como foco resgatar a liberdade das pessoas envolvidas na dinâmica educativa e investigativa a que se refere, ao romper, extirpar e superar as marcas colonialistas de dentro de cada pessoa colonizada.

Esse processo se configura como ação, por meio da qual a educação se coloca como algo maior e mais complexo que a escolarização. Nesse ponto, a Fenomenologia Schiller-Goethiana se apresenta como referencial fundamental na medida em que busca no mais íntimo de cada pessoa envolvida, argumentos e meios que atendam aos anseios postos pela vida em relação e interação, tanto com referenciais de materialidade, de imaterialidade e de amaterialidade (KEIM, 2019b).

Essa possibilidade própria dessa abordagem investigativa e educativa tem como foco de atuação a tríade intensificação, sensibilização e ritmo que originalmente é representada pela expressão Steigerung, no idioma alemão, e que é representada na língua portuguesa com a expressão Paranauê (KEIM, 2018a), pelo fato de ela apontar para a dança da Capoeira, que está implicada com seus referenciais, ou seja: intensificação, sensibilização e ritmo.

\footnotetext{
Essa posição se referência na perspectiva de que a ação humana junto à natureza se desenvolve a partir da intensificação, da sensibilização e da percepção e acolhida do ritmo, com que cada elemento que constitui a natureza se manifesta diferentemente a cada momento, e a cada evento como possibilidade de interação, altamente complexa e caótica (KEIM, 2018a, p. 08).
}

De acordo com Keim (2018a), a sensibilização é destacada como processo que possibilita alcançar a consciência, a imaginação, a intuição e a fantasia, inerentes ao tema e aos integrantes que promovem a vida dos integrantes da comunidade educativa. A sensibilização integrada à intensificação e aos ritmos caracterizam-se como envolvimento para compreender os meandros da imaginação, de forma que: 
- Intensificação: se configura com o aumento do ritmo para refinar aquilo que se pretende obter, para alcançar melhorias provisórias, as quais se somam ao já estabelecido, num processo infinito e eterno. Intensificar é reconhecer a dinâmica caótica e quântica da dinâmica eco-reorganizativa que constitui o Cosmo.

- Sensibilização: se manifesta como algo que se coloca em processo de metamorfose, sem se acomodar nem se colocar acima de tudo que um humano humanizado conhece e reconhece.

- Ritmo: possibilita compreender e estabelecer uma harmonia na desordem, se caracterizando como possibilidade de dar vida e de reconhecer a vida em sintonia com a plenitude (KEIM, 2018a, p. 27).

No contexto da Educação da Emancipação a favor da Vida, referenciada na Fenomenologia Schiller-Goethiana, movida pela valorização da pessoa e o seu processo de humanização, a educação se constitui como uma cosmovisão, considerando que:

[...] cosmovisão se caracteriza como uma postura pessoal e coletiva, de olhar o mundo, para dentro do mundo. É uma ação de como cada pessoa, a partir de seu grupo social e de sua herança ancestral se sente mergulhada, no que considera como sendo seu mundo. Assim, Cosmovisão é muito mais que um olhar o mundo, é um olhar para o mundo, é um olhar do mundo para si mesmo, sendo você o mundo como parte integrada ao mundo, por isso se vê. É um olhar atento e assumido para o que vem a ser o seu mundo, construído com base nos conhecimentos ancestrais e nas tradições, costumes e crenças construídas e consolidadas pelos seus pares (KEIM, 2019a, p. 03).

Partindo de uma interação com grupo de estudos liderado por Frei Leonardo Boff e iniciada na década de 1970, Keim desenvolveu um conjunto de aspectos que se caracterizam como imprescindíveis para a vida com dignidade, o que foi nomeado como Princípios Eco-Vitais. Estes se configuram, como referenciais para uma vida de qualidade e plenitude que atendem à condição ontológica e existencial das pessoas e dos demais integrantes ambientais. Esses princípios são aspectos dos quais não se pode abrir mão, sendo uma proposição que referenda a condição humana como ser de direito, inalienável, para que todas as pessoas possam usufruir com dignidade de: Alimento, Abrigo, Ocupação, Afeto, Partilha, Cuidado, Pertencimento e Espiritualidade (KEIM, 2018b).

Nesse conjunto de referências, a Educação da Emancipação a favor da Vida se apresenta como uma abordagem educativa e Emancipatória, em síntese, caracteriza-se no exercício cognitivo que tem como foco educar o olhar para o outro e para o mundo, na tentativa de superar a visão egocêntrica que gera preconceitos e exclusão. A educação nessa perspectiva, consolida-se na medida em que cada pessoa busca compreender que viver é ampliar sua sensibilidade quanto aos potenciais de relação e de responsabilidade inerentes à interação com tudo que está em volta, ou seja, estamos constantemente em processo educativo com o mundo. 
A ciência da motricidade humana como referencial curricular na educação física escolar

A Ciência da Motricidade Humana floresce com as inquietações do filósofo e pesquisador lusitano Manuel Sérgio Vieira e Cunha, ao apresentar sua tese de doutoramento, intitulada "Para uma Epistemologia da Motricidade Humana”, pelo Instituto Superior de Educação Física da Universidade Técnica de Lisboa, em 1986. Essa abordagem visa à superação da dualidade corpo e mente presente nas interpretações das ciências do homem (SÉRGIO, 1995).

O referido pesquisador propõe com a Ciência da Motricidade Humana, a transição do paradigma cartesiano, disjuntivo e simplificador, rumo ao paradigma sistêmico, no qual o movimento humano ganha sentido. Manuel Sérgio acredita que

[...] com a ciência da motricidade humana, os praticantes do desporto, dança, ergonomia e educação especial não se comportem mais como simples máquinas, animadas dos exercícios físicos que a sociedade lhes impõe, mas como pessoas livres e libertadoras; solitárias e solidárias; atentas ao que nelas mesmas é biológico, cultural e ânsia inapagável de transcendência, de ser mais (SÉRGIO, 1995, p.13).

Compreender o ser humano de acordo com essa proposta teórica, caracteriza-se como uma investigação que interroga a manifestação do fenômeno humano, em busca de compreensão de sua essência, e nesse sentido Manuel Sérgio declara o ser humano como um ser cultural, inteligível, carente, práxico, e com ânsia de transcendência de ser mais (SÉRGIO, 1995).

No aspecto cultural, elemento fundamental da condição humana, que vai além de a herança biológica, Manuel Sérgio (1995) considera o ser humano com atributos que o possibilita ser maleável e modificável por educação. O referido autor destaca a educação como meio de realização cultural do ser humano, de tal modo que ele e a cultura se confundem, sendo inconcebível à humanidade sem as invenções decorrentes das dinâmicas e possibilidades culturais.

Diante da complexidade que caracteriza o humano, Manuel Sérgio (1995) cita que por ser inteligível, o ser humano age intencionalmente e envolve a sua conduta em um contexto de sentido, superando a relação sujeito-objeto para uma relação de ser, na qual o sujeito é seu corpo, seu mundo e sua situação, o mundo vivido interior e intersubjetivamente.

Compreendendo o ser humano como um ser carente, Manuel Sérgio (1995) considera que o humano visa a todo o instante, passar do reino da necessidade ao reino da liberdade, e ele supera suas carências, agindo como um ser práxico.

Nesta abordagem fenomenológica, a percepção é o veículo de comunicação e diálogo com o mundo. De forma sintética "perceber é tornar presente qualquer coisa com ajuda do corpo", pois "eu não estou diante do meu corpo, estou no meu corpo, ou melhor, sou meu corpo" (MERLEAUPONTY apud SÉRGIO, 1995, p. 25). 
Em suas buscas investigativas para entender os preceitos da complexidade humana, Manuel Sérgio (2010) apresenta os seguintes elementos: corpo-mente-desejo-natureza-sociedade. Para Manuel Sérgio é impossível isolar a pessoa do seu ecossistema, o indivíduo da sociedade e da natureza, e o sujeito do objeto. Assim, como no sujeito, o físico dos demais elementos que o compõem, sistemas: nervoso, cardiovascular, respiratório, esquelético, entre outros.

Considerando os elementos descritos, Manuel Sérgio (1995) expõe o seu embasamento das dimensões humanas:

[...] corporeidade (o Homem é presença e espaço na história, como corpo, no corpo, desde o corpo e através do corpo); na motricidade (que é virtualidade para o movimento intencional, que persegue a transcendência); na comunicação e cooperação (o sentido do outro nasce da sua indispensabilidade ao meu estar-no-mundo); na historicidade (a historicidade do homem consiste no fato de ele não poder conhecer-se, com uma análise exclusiva do presente, pois que vem de um passado-recordação, que o motiva para um futuro-esperança, onde se projeta); na liberdade (passar do reino da necessidade ao reino da liberdade é a expressão omnilateral de um sujeito histórico, simultaneamente reflexo e projeto); na noosfera (ou reino do espírito e da cultura, onde a especialização dos vários saberes readquire o sentido da totalidade humana); na transcendência (ser humanamente é agir para ser mais) (SÉRGIO, 1995, p. 22).

O Prof. Dr. Carol Kolyniak Filho, pesquisador experiente da Ciência da Motricidade Humana, apresenta a explicação da transcendência com base no conceito de Manuel Sérgio, dizendo que:

Transcendência: o que está além, ou fora, da realidade dada, daquilo que realmente pode esperar-se. Opõe-se à imanência. O ser humano, através da sua motricidade, prova que é um ente que anseia pela transcendência, pela capacidade de ser mais e de ser melhor. Porque sei que me posso transcender, procuro a invenção de um Futuro que não seja a dedução do que já existe, mas a emergência de novas possibilidades. Pela transcendência, o ser humano faz-se sujeito e não objeto da História. (SÉRGIO apud KOLYNIAK FILHO, 2018, p. 22).

Para Kolyniak Filho (2018, p. 22), diante desse conceito, Manuel Sérgio não atribui um sentido metafísico ou religioso à transcendência, "O foco da definição está na busca da superação de limites da realidade dada, dos limites existentes em dado momento, tanto no sujeito como nas circunstâncias".

Com base nas constatações da Ciência da Motricidade Humana, na qual considera a visão holística do homem, diante da tomada de consciência de que não é objeto, mas sujeito fazedor da história, em diálogo constante com o mundo, doador de sentido pela práxis transformadora de si mesmo, extensivo na coletividade e em um desejo inseparável de transcendência, o presente estudo considera este campo do conhecimento como um paradigma emergente, um corte epistemológico na área da Educação Física, que se configura também como campo disciplinar, e como um salto qualitativo em relação ao dualismo e ao mecanicismo, racionalista. 
Na Educação Motora, ramo pedagógico da Ciência da Motricidade Humana, segundo Manuel Sérgio (1995), o movimento se caracteriza como status ontológico, em busca incessante da transcendência, em que a pessoa tem ensejo de pôr à prova suas qualidades físicas e a sagacidade, a perspicácia, a inventividade, a afetividade, a inteligência, entre outras capacidades humanas.

[...] porque no movimento da transcendência o praticante se sente permanentemente inacabado, ele está em incessante diáspora, ele pratica, não uma disciplina, mas uma indisciplina - uma disciplina que nos remete ao corpo no ato poético da criatividade. A motricidade humana é bem a expressão corporal da incompletude! (SÉRGIO, 1995, p. 58).

Diante dessa natureza teórica, metodológica e prática, a Educação Motora se caracteriza como um agir com intencionalidade para ser mais, e o ser humano, por ser axiotrópico, ou seja, aquele que persegue, apreende, cria e realiza valores, é intrinsecamente cultural, pois conhece e se conhece, e transforma e se transforma.

Essa perspectiva, no chão da escola, nas aulas de Educação Física com base no paradigma da Motricidade Humana, considera tempo, espaço e conhecimento, como num laboratório de reconhecimento do potencial de pertencimento e interação das pessoas entre si, visto que cada aula pode favorecer vivências em um movimento de transcendência. Sendo este o sentido das aulas de Educação Motora que são "[...] difíceis e belas, onde se cria e convive com a incerteza, com a inquietação, com o sonho, com a alegria, com a gratuidade, com a vontade de ir mais além” (SÉRGIO, 1995, p. 62).

Educação da emancipação a favor da vida (educação ambiental) na educação física escolar

A Ciência da Motricidade Humana, como processo capaz de estimular a dimensão da Educação da Emancipação a favor da Vida no contexto da Educação Física Escolar (SANTOS, 2019, p. 81), reúnem argumentos referentes à Educação da Emancipação a favor da Vida que foram construídos com base nos princípios da Educação Ambiental propostos na Carta de Belgrado (UNESCO, 1975). Esse documento impulsionou as diretrizes da Educação Ambiental em diversos países, inclusive no Brasil, numa vertente subjetiva e objetiva focada na vida com dignidade.

Cabe destacar que esse texto apoia a Educação Ambiental com base na Carta de Belgrado (UNESCO,1972), pelo fato de esse documento alcançar aspectos que têm sintonia com as formas como Manuel Sérgio debate os sistemas econômicos de produção e distribuição, com foco nas responsabilidades que devem ser creditadas para o capital e não ao humano, o qual da mesma forma que a vida é vítima sujeitada à guerra de classes desencadeada pelos sistemas monopolísticos de poder. Assim, esse documento trata a temática ambiental com foco na necessidade de uma nova 
ética global, individual e coletiva, que reconheça a dinâmica e a complexidade nas relações entre humanos e natureza e entre seus semelhantes.

Uma proposta decorrente da pesquisa que sustenta esse texto, é a possibilidade de professores de Educação Física refletirem sobre as competências da Educação Física citadas pela Base Nacional Comum Curricular e a relação com sua prática pedagógica, fundamentada em aspectos que estimulem a inserção de referenciais focados na Emancipação a favor da Vida com dignidade.

Essa proposição com viés de interação e complementaridade entre a Ciência da Motricidade Humana e a Educação da Emancipação a favor da Vida, tem vínculos com a pedagogia freiriana conforme apresentados no Quadro 01, cujo conteúdo aponta para o ser humano em sua mundialidade, entendendo que se educam pessoas que concentram em si, simultaneamente, corpomente-desejo-natureza-sociedade, em um apelo incessante à transcendência.

Assim, a publicação desse quadro pode contribuir para que os professores de Educação Física e das demais áreas do conhecimento, reflitam criticamente sobre a forma como essas duas abordagens teóricas possam ampliar o entendimento das competências com foco na humanização e na postura de responsabilidade com a vida, desencadeada pelas ações educativas no ambiente escolar. Cabe destacar que esse material é apenas referencial para reflexão que pode gerar mudanças nas ações educativas escolares, para promover ações que ampliem a consciência da responsabilidade com a vida planetária.

O resultado desse estudo teórico exploratório, sintetizado no Quadro 01, no qual se utilizou a base de estrutura para o estudo (CRESWELL, 2010), apresenta o diálogo crítico e propositivo entre a Educação da Emancipação a Favor da Vida e a Ciência da Motricidade Humana (SANTOS, 2019, p. 85). Na categoria da Educação da Emancipação a favor da Vida, os pressupostos elencados são os resultados da análise da interação dessa abordagem educativa com as Diretrizes Básica dos programas de Educação Ambiental, elencados na Carta de Belgrado (UNESCO, 1975). Os aspectos da Ciência da Motricidade Humana foram elaborados com base na leitura crítica das dez competências da Educação Física citada na Base Nacional Comum Curricular (BRASIL, 2018), interpretados com os argumentos da Ciência da Motricidade Humana (SÉRGIO, 1995, 2001, 2010). 
Quadro 01 -Aspectos de complementaridade e interação entre os pressupostos da educação da Emancipação da vida e os pressupostos da ciência da motricidade humana:

Continua

\begin{tabular}{|c|c|c|}
\hline & $\begin{array}{l}\text { Pressupostos da Educação da Emancipação a } \\
\text { favor da Vida (EEV): }\end{array}$ & $\begin{array}{l}\text { Referenciais da CMH (Ciência da } \\
\text { Motricidade Humana), conforme } \\
\text { Manuel Sérgio: }\end{array}$ \\
\hline 01 & $\begin{array}{l}\text { A EEV se refere ao que devemos aprender com } \\
\text { os ambientes e com a vida. Considerando o } \\
\text { ambiente em sua totalidade - natural e criado pelo } \\
\text { homem, ecológico, econômico, tecnológico, social, } \\
\text { legislativo, cultural, estético, acrescido do político, } \\
\text { religioso e da corporeidade. }\end{array}$ & $\begin{array}{l}\text { Na motricidade humana o movimento é } \\
\text { status ontológico, em busca incessante da } \\
\text { transcendência, agir com intencionalidade } \\
\text { para ser mais, e o ser humano, por ser } \\
\text { axiotrópico (que persegue, apreende, cria e } \\
\text { realiza valores), sendo intrinsecamente } \\
\text { cultural, conhece, se conhece, transforma e } \\
\text { se transforma. }\end{array}$ \\
\hline 02 & $\begin{array}{l}\text { A EEV é compreendida como um processo } \\
\text { contínuo, permanente, tanto dentro como fora da } \\
\text { escola, em que se configura uma postura de cada } \\
\text { pessoa diante da interação com a vida. }\end{array}$ & $\begin{array}{l}\text { Compreender o desporto, a dança, o jogo, a } \\
\text { ginástica etc., como sistemas abertos de } \\
\text { aprendizagem, visto que se desenvolvem na } \\
\text { relação de comunicação, decorrentes da } \\
\text { CMH. De forma dialógica com o mundo, } \\
\text { deve tornar-se visível a construção social da } \\
\text { pessoa em interação nos diferentes } \\
\text { ambientes de aprendizagem. }\end{array}$ \\
\hline 03 & $\begin{array}{l}\text { A EEV adota o método disciplinar, multi e o } \\
\text { transdisciplinar. }\end{array}$ & $\begin{array}{l}\text { Fomentar a transdisciplinaridade evitando a } \\
\text { fragmentação do saber. Considerando as } \\
\text { particularidades das intenções motoras } \\
\text { (esporte, dança, jogo, luta, ginástica). } \\
\text { Porém, salientando, a autonomia, a } \\
\text { criatividade, a relação, a ética e a linguagem, } \\
\text { visando uma perspectiva sistêmica na qual a } \\
\text { complexidade seja presente. }\end{array}$ \\
\hline 04 & $\begin{array}{l}\text { A EEV enfatiza a participação ativa na prevenção e } \\
\text { solução dos problemas ambientais, considerando a } \\
\text { necessidade de nos reconhecermos, também, como } \\
\text { um ser político, consciente das forças e poderes que } \\
\text { sofre e exerce para então promover mudanças no } \\
\text { modelo civilizatório no qual estamos imersos. }\end{array}$ & $\begin{array}{l}\text { Surgir como um sinal de resistência ao } \\
\text { irracionalismo da barbárie fascista, do } \\
\text { dogmatismo neoliberal e à semicultura do } \\
\text { corporativismo dado que o ser humano, em } \\
\text { movimento intencional, reflete e projeta } \\
\text { valores. }\end{array}$ \\
\hline 05 & $\begin{array}{l}\text { A EEV aponta para o desafio de construção da } \\
\text { cidadania planetária, referenciada nos Princípios } \\
\text { Eco-Vitais como exigência primária em } \\
\text { disponibilizar a todos os humanos recursos } \\
\text { necessários à vida digna e plena (abrigo, ocupação, } \\
\text { afeto, partilha, cuidado, pertencimento e } \\
\text { espiritualidade). }\end{array}$ & $\begin{array}{l}\text { Considerando o processo adaptativo, } \\
\text { evolutivo e ativo, a visão sistêmica do } \\
\text { homem (corpo-alma-natureza-sociedade), } \\
\text { aberto ao Mundo, aos Outros e à } \\
\text { Transcendência, desperta para o surgimento } \\
\text { de uma nova antropologia. Depois de o } \\
\text { homem ter conquistado e devastado a } \\
\text { Natureza, volta-se agora para si mesmo em } \\
\text { um processo inteligível quando se percebe } \\
\text { que o sentido da vida humana consiste na } \\
\text { passagem do ser ao dever-se, isto é, } \\
\text { perceber-se como pessoa responsável pela } \\
\text { vida planetária. }\end{array}$ \\
\hline
\end{tabular}




\begin{tabular}{|l|l|l|}
\hline \multirow{2}{*}{06} & $\begin{array}{l}\text { A EEV se baseia na realidade concreta para } \\
\text { modificá-la a favor da vida com dignidade, }\end{array}$ & $\begin{array}{l}\text { A pessoa se reconhecer corpo-mente- } \\
\text { desejo-natureza-sociedade como um todo }\end{array}$ \\
& $\begin{array}{l}\text { considerando dilemas e desafios pautados no social, } \\
\text { na materialidade e na historicidade. Emancipar o ser } \\
\text { humano para a dimensão planetária de forma a se } \\
\text { integrado e dinâmico, ou seja, a pessoa se } \\
\text { comprometer com a vida, colocando-se como parte, } \\
\text { e não como o centro de todo o processo vital. }\end{array}$ & $\begin{array}{l}\text { reconhecer como um ser que pensa, sente e } \\
\text { pelo movimento realiza a intenção } \\
\text { primordial de viver com responsabilização. }\end{array}$ \\
\hline
\end{tabular}

Fonte: Santos, 2019, p. 85.

Dessa forma, os aspectos de complementaridade entre a Ciência da Motricidade Humana e a Educação da Emancipação a favor da Vida, conforme apresentado no quadro, caracterizam-se como uma possibilidade de subsidiar a prática docente em Educação Física que reconheça a existência da pessoa, crianças, jovens, adultos e idosos, em constante processo de aprendizagem e diálogo com o mundo.

Com base no levantamento teórico e nas análises realizadas, a investigação que sustenta esse texto, apontam para a educação no contexto escolar em outra lógica, ou seja, uma educação que busca a valorização da existência humana, permeada pela amorosidade e postura de responsabilidade, mediante o processo de Emancipação e libertação a favor da vida com dignidade. A educação, nessa perspectiva, reconhece que as competências examinadas de modo crítico, podem ser potenciais para o desenvolvimento da inteligência, intuição, criatividade e autonomia dos estudantes e valoriza a motricidade humana como processo dinâmico de aquisição do saber, de construção da saúde, de despertar potencialidades adormecidas e de descoberta de nós mesmos, do outro e do ambiente.

Os elementos resultantes apresentados nesse estudo teórico exploratório, corroboram com as considerações de Kolyniak (2018, p. 22), acerca do tema que tem emergido recentemente nas discussões no âmbito da Ciência da Motricidade Humana, à espiritualidade. Uma espiritualidade que tem base no campo das ciências emergentes, tais como a Física Quântica e a Fenomenologia Schiller-Goethiana, na qual as elaborações apoiadas em dados empíricos permitem questionar a ideia de que a realidade objetiva se esgota na matéria, tal qual percebida pelos sentidos humanos e pelos instrumentos criados para ampliá-los.

\section{Apontamentos conclusivos}

Motivada em desencadear ações educativas e Emancipatórias, a perspectiva da Ciência da Motricidade aliada à Educação da Emancipação da Vida, refere-se ao conhecimento que almeja superar a concepção de Educação Ambiental preservacionista, e o olhar fragmentário nas relações entre o ser humano, a sociedade e a natureza. Entender o ser humano na sua integralidade passa a 
ser o desafio apontado no estudo, especialmente para o profissional que almeja fazer uma leitura crítica e questionadora das competências da Base Nacional Comum Curricular, transitando da visão linear, mecanicista, dualista e reducionista, centrada em educar o físico das pessoas, para a visão de uma educação que concentra em si, simultaneamente, corpo-mente-desejo-natureza-sociedade.

Essa abordagem de Educação Física pode favorecer, em cada pessoa, o reconhecimento dos poderes e forças promotoras de emoções, sentimentos, ideias, compreensões, criatividade, intuição, entre outras formas que nos caracterizam como humanos capazes de interagir e alterar o mundo.

Em síntese, a educação nessa cosmovisão implica compreender que a Educação Física é um componente curricular que, se realizada no concreto da vida e na dinâmica das interações, tem como premissa despertar o ser humano em potência, existente em cada educando que na motricidade realiza à transcendência.

\section{Referências}

BRASIL. Conselho Nacional de Educação Diretrizes Curriculares Nacionais para a Educação Ambiental. Resolução CNE/CP nº 2, de 15 de junho de 2012. Brasília, Diário Oficial [da] República Federativa do Brasil,18 de junho de 2012, Seção 1, p. 70 - 71. Disponível em: rcp002_12 (mec.gov.br). Acesso em: 24 maio 2021.

BRASIL, Ministério da Educação. Secretaria da Educação Básica. Base Nacional Comum Curricular. Brasilia-DF, 2018. Disponível em: Início (mec.gov.br). Acesso em: 24 maio 2021.

CRESWELL, J. W. Projeto de pesquisa: métodos qualitativo, quantitativo e misto. Tradução por: Magda Lopes - 3. ed. - Porto Alegre: Artmed, 2010.

DOMINGUES, Soraya Corrêa. Formação em Educação Física na Dimensão da Educação Ambiental. Curitiba: CRV, 2021.

DOMINGUES, Soraya Corrêa. A dimensão da educação ambiental na teoria e prática pedagógica da formação de professores em Educação Física. 2011. 319 f. (Doutorado em Educação Física) - Centro de Desporto, Universidade Federal de Santa Catarina, 2011.

FREIRE, Paulo. Pedagogia do Oprimido. 42. ed. Rio de Janeiro: Paz e Terra, 2005.

KOLYNIAK, Carol Filho. Prefácio. In: FERES NETO, Alfredo (Org.) Motricidade Humana: novos olhares e outras práticas: à luz da transdisciplinaridade e das ciências emergentes. Curitiba: Appris, 2018. p. 19-26.

KEIM, Ernesto Jacob. Educação Ambiental como Educação do Ambiente e da Emancipação da Vida, referenciada nos Principios Eco-Vitais. Matinhos, jun. 2019a. Disponível em:

http://profjacob.com.br/bloco-2/. Acesso em: 20 jun. 2019. 


\section{Dialogia}

SANTOS, Reard Michel dos; KEIM, Ernesto Jacob; DOMINGUES, Soraya Corrêa. Educação ambiental uma proposta emancipatória na educação física escolar

KEIM, Ernesto Jacob. A Fenomenologia Goethiana na Educação e na Pesquisa como agente de Metamorfose. Matinhos, 24 jun. 2019b. Disponível em: http://profjacob.com.br/bloco-3/. Acesso em: 24 jun. 2019.

KEIM, Ernesto Jacob. Pedagogia Freiriana e Goethiana como processo anticolonial. Matinhos, jun. 2018a. Disponível em: http://profjacob.com.br/bloco-4/ Acesso em: 24 jun. 2019.

KEIM, Ernesto Jacob. Princípios Eco-Vitais como referenciais do Bem Viver na educação da Emancipação. Matinhos, 24 fev. 2018b. Disponível em: http://profjacob.com.br/wpcontent/uploads/2018/03/O-BEM-VIVER-E-OS-PRINC\%C3\%8DPIOS-ECO-revisado.pdf. Acesso em: 24 jun. 2019.

KEIM, Ernesto Jacob. Ontologia de Steiner e Freire e o Bem Viver como agentes de Libertação por meio da Educação. In: VEIGA, Marcelo da; STOLTZ, Tânia (org.). O Pensamento de Rudolf Steiner no Debate Cientifico. Campinas: Alínea, 2014. p. 181-211.

KEIM, Ernesto Jacob. Educação da Insurreição: Emancipação humana, ontologia e pedagogia em Georg Lukács e Paulo Freire. Jundiaí, Paco Editorial: 2011.

KUNZ, Elenor. Transformações didático-pedagógica do esporte. 6. ed. Ijuí: Ed. Unijuí, 2004.

MERLEAU-PONTY, Maurice. Psicologia e pedagogia da criança. Tradução Ivone C, Benedetti. São Paulo: Martins Fontes, 2006.

MERLEAU-PONTY, Maurice. A Natureza. Trad.: Álvaro Cabral. São Paulo: Martins Fontes, 2000.

MERLEAU-PONTY, Maurice. A estrutura do comportamento (J. Corrêa, Trad.). Belo Horizonte: Interlivros. 1975

NEIRA, M. G. Incoerências e inconsistências da BNCC de Educação Física. Revista Brasileira de Ciências do Esporte, v. 40, n. 3, p. 215-223, 2018a. Disponível em:

https://doi.org/10.1016/j.rbce.2018.04.001. Acesso em: 24 maio 2021.

ORGANIZAÇÃO DAS NAÇÕES UNIDAS PARA A EDUCAÇÃO, A CIÊNCIA E A CULTURA (UNESCO). Carta de Belgrado: Uma estrutura global para a educação ambiental. 1975. Disponível em: http://www.fzb.rs.gov.br/upload/20130508155641carta_de_belgrado.pdf. Acesso em: 24 jun. 2019.

SANTOS, Reard Michel. A Motricidade Humana e Educação da Emancipação da Vida na Educação Física Escolar. 2019. 110f. Dissertação (Mestrado Profissional em Ciências Ambientais), Universidade Federal do Paraná, Setor Litoral, Matinhos, 2019. Disponível em: A motricidade humana e educação da Emancipação da vida na educação física escolar (ufpr.br). Acesso em: 27 maio 2021.

SÉRGIO, Manuel. O desporto e a motricidade humana. Caderno de Educação Física, Marechal Cândido Rondon, v.9, n. 16, p. 111-122, jan./jun. 2010. Disponível em: O DESPORTO E A MOTRICIDADE HUMANA | Sérgio | Caderno de Educação Física e Esporte (unioeste.br) Acesso em: 27 maio 2021. 


\section{Dialogia}

SANTOS, Reard Michel dos; KEIM, Enesto Jacob; DOMINGUES, Soraya Corrêa. Educação ambiental uma proposta emancipatória na educação física escolar

SÉRGIO, Manuel. Motricidade humana e saúde. Revista da Educação Física/ UEM, Maringá, v.12, n. 2, p. 129 - 138, jan./jun. 2001. Disponível em: https://periodicos.uem.br/ojs/index.php/RevEducFis/article/view/3783/2589. Acesso em: 27 maio 2021.

SÉRGIO, Manuel. Motricidade humana: um paradigma emergente. Blumenau: Ed da FURB, 1995. 